\title{
BMJ Open Uncertainty and the reporting of intellectual disability on death certificates: a cross-sectional study of US mortality data from 2005 to 2017
}

\author{
Scott D Landes (D) , ${ }^{1}$ Margaret A Turk, ${ }^{2}$ Erin Bisesti ${ }^{1}$
}

To cite: Landes SD, Turk MA, Bisesti $\mathrm{E}$. Uncertainty and the reporting of intellectual disability on death certificates: a cross-sectional study of US mortality data from 2005 to 2017. BMJ Open 2021;11:e045360. doi:10.1136/ bmjopen-2020-045360

- Prepublication history for this paper is available online. To view these files, please visit the journal online (http://dx.doi. org/10.1136/bmjopen-2020045360).

Received 28 September 2020 Revised 11 January 2021 Accepted 19 January 2021

Check for updates

(C) Author(s) (or their employer(s)) 2021. Re-use permitted under CC BY-NC. No commercial re-use. See rights and permissions. Published by BMJ.

${ }^{1}$ Department of Sociology and Aging Studies Institute, Maxwell School of Citizenship and Public Affairs, Syracuse University, Syracuse, New York, USA ${ }^{2}$ Department of Physical Medicine and Rehabilitation, SUNY Upstate Medical University, Syracuse, New York, USA

Correspondence to Professor Scott D Landes; sdlandes@maxwell.syr.edu

\section{ABSTRACT}

Objective To investigate whether uncertainty surrounding the death is associated with the inaccurate reporting of intellectual disability as the underlying cause of death. Design National Vital Statistics System 2005-2017 US Multiple Cause-of-Death Mortality files.

Setting USA.

Participants Adults with an intellectual disability reported on their death certificate, aged 18 and over at the time of death. The study population included 26555 adults who died in their state of residence between 1 January 2005 and 31 December 2017.

Primary outcome and measures Decedents with intellectual disability reported on their death certificate were identified using the International Statistical Classification of Diseases and Related Health Problems, Tenth Revision code for intellectual disability (F70-79). Bivariate analysis and multilevel logistic regression models were used to investigate whether individual-level and state-level characteristics indicative of increased uncertainty at the time of death were associated with the inaccurate reporting of intellectual disability as the underlying cause of death.

Results Inaccurate reporting of intellectual disability as the underlying cause of death was associated with sociodemographic characteristics, death context characteristics and comorbidities indicative of an increased amount of uncertainty surrounding the death. Most striking were increased odds of having intellectual disability reported as the underlying cause of death for decedents who had a choking event $(0 \mathrm{R}=14.7 ; 95 \%$ Cl 12.9 to 16.6, $p<0.001$ ), an external cause of death associated with a high degree of uncertainty, reported on their death certificate.

Conclusion It is imperative that medical personnel not let increased uncertainty lead to the inaccurate reporting of intellectual disability as the underlying cause of death as this practice obscures cause of death trends for this population. Instead, even in instances when increased uncertainty surrounds the death, certifiers should strive to accurately identify the disease or injury causing death, and report the disability in Part II of the death certificate.

\section{INTRODUCTION}

People with intellectual disability (ID), a population under-represented in medical and public

\section{Strengths and limitations of this study}

- The first study to explore individual-level and statelevel characteristics associated with inaccurate reporting of intellectual disability as the underlying cause of death on the death certificate.

- Study population does not include all adults with intellectual disability who died in the USA.

- High number of cases reporting 'unspecified intellectual disability' on the death certificate limited the ability to assess the full effect of types of intellectual disability on inaccurate reporting.

health research, experience disparities in healthcare. ${ }^{1-3}$ One practice that lends to these disparities is diagnostic overshadowing-stereotypically attributing physical or mental health problems to the disability, neglecting the reality that symptoms may originate from diseases or illnesses distinct from the disability. ${ }^{4-6}$ Diagnostic overshadowing prevents people with ID from receiving needed medical care, and is a common experience for this population across the life course. ${ }^{6-8}$

Diagnostic overshadowing extends into death for people with ID. The US Standard Certificate of Death, commonly referred to as the Death Certificate, provides demographic information about the decedent (eg, age, biological sex, race-ethnicity), the diseases or injuries that were part of the chain of events leading to death, and other significant conditions present at the time of death. ${ }^{9}$ In the USA, between 2012 and 2016, $25.9 \%$ of the death certificates that reported the decedent had ID inaccurately identified this disability as the underlying cause of death (UCOD). ${ }^{10}$ As a disability, ID does not qualify as an UCOD as defined by the Centers for Disease Control and Prevention (CDC) - 'a disease or injury that initiated the train of morbid events leading directly to death'. ${ }^{11}$ Instead, ID is a disability involving limitations in intellectual functioning and adaptive behaviour that 
commences before age $18 .^{12}$ As such, in the majority of circumstances, ID should be reported in Part II of the US death certificate. ${ }^{13}$ Per CDC guidelines, Part II of the death certificate is intended for conditions present at the time of death that may have, directly or indirectly, contributed to the death. ${ }^{11}$ However, it is important to recognise that there may be rare instances in which the person certifying the death certificate is justified in concluding that the disability in no way, directly or indirectly, contributed to the death, and thus deciding to not report ID on the death certificate at all. ${ }^{13}$

Beyond its inaccuracy, the reporting of ID as the UCOD also represents a lost opportunity for prevention efforts focused on premature mortality among this population. In the USA, adults with ID die at ages 9-13 years earlier than their peers without this disability, ${ }^{14}$ often from preventable causes of death. ${ }^{10}$ Inaccurately reporting ID as the UCOD obscures higher rates of possibly preventable causes of death such as influenza and pneumonia, pneumonitis, and choking. ${ }^{10}$ Since efforts to reduce premature death typically rely on death certificate data to understand mortality trends, ${ }^{15}$ it is imperative to eliminate the practice of inaccurately reporting ID as the UCOD. Otherwise, it is impossible to garner an accurate accounting of actual cause of death trends for this population.

There is evidence that the level of uncertainty surrounding the death affects the accuracy of death certification. ${ }^{16}{ }^{17}$ The amount of uncertainty surrounding the death is at least partially determined by the place of death. In non-medical settings such as the home, less medical information is immediately available and more uncertainty is present. ${ }^{1618}$ The amount of uncertainty surrounding the death may also increase or decrease based on the experience level of the certifier - with medical examiners typically more experienced at death certification than other medical professionals ${ }^{1920}$-or whether an autopsy was performed. ${ }^{21}{ }^{22}$ Yet, beyond these proximal factors, the amount of uncertainty surrounding the death is largely informed by the number of comorbidities chronicled in the decedent's prior medical record, with more uncertainty present for decedents with a sparse or incomplete disease history. ${ }^{16-18}$ This association is most apparent in research that shows more errors on death certificates that report fewer comorbidities, or on death certificates that report unspecified diseases or external causes of morbidity, rather than specified internal causes of morbidity. ${ }^{16-18}$ Looking more upstream to understand differences in the documentation of disease history, less thorough medical records are likely among decedents with sociodemographic characteristics indicative of reduced frequency or quality of lifetime physician-patient interaction, ${ }^{18}{ }^{23}$ such as younger age,${ }^{18}$ Hispanic ethnicity, ${ }^{24-26}$ lower levels of education $^{2728}$ and more severe levels of disability. ${ }^{2-31}$ Though not explored to date, the thoroughness of the medical records for people with ID may also be associated with the level of interaction and familiarity that medical personnel have with this population in their geographic locale. ${ }^{32}$

Some errors may be due to medical providers, especially those with limited knowledge of ID, being unsure about where to report ID on the death certificate. ${ }^{10} 1633$ This may result in instances where the certifier is justified to report the ID on the death certificate, but fails to do so, or instances where the certifier inaccurately reports ID as the UCOD. To address this general uncertainty, a recent paper provides clear guidance on how to accurately report ID, as well as other developmental disabilities, on the death certificate. ${ }^{13}$ While an important first step, it is necessary to understand the specific factors present at the time of death that may increase uncertainty and lead medical providers to inaccurately report ID as the UCOD. We build on prior research to identify the individual-level and state-level factors associated with the inaccurate reporting of ID as the UCOD. It is our expectation that the inaccurate reporting of ID as the UCOD will be more likely to occur in situations associated with limited information about the decedent's medical history and/or limited knowledge about ID, leading to a higher degree of uncertainty.

\section{METHODS \\ Data}

This study used National Vital Statistics System restricted-use 2005-2017 US Multiple Cause-of-Death Mortality files. Multiple years were used to ensure sufficient cell counts per variable, with 2005 being the earliest year in which geographic identifiers are available. As analysis focused on individual-level and state-level predictors of ID as the UCOD, this study included the death certificates of adults, aged 18 and over, who had an International Statistical Classification of Diseases and Related Health Problems, Tenth Revision (ICD-10) code for ID (F70-79) reported as the underlying or a multiple cause of death, and who died in their state of residence between 1 January 2005 and 31 December 2017 ( $\mathrm{n}=26555)$.

Data on state intellectual and developmental disability (IDD) fiscal spending were obtained from State of the States in Intellectual and Developmental Disabilities. ${ }^{34}$

\section{Measures}

The outcome measure for this study is a binary variable that indicates whether ID was inaccurately reported as the UCOD (yes; no).

The amount of uncertainty surrounding the cause of death was captured using individual-level and statelevel measures. Three measurement concepts defined individual-level measures: sociodemographic characteristics, death processing, and comorbidities.

\section{Sociodemographic characteristics}

Four measures account for individual-level sociodemographic characteristics associated with the amount of information available regarding the decedent's medical history: severity level of ID (mild/moderate; severe/profound; other/unspecified); age (18-29; 30-39; 40-49; 50-59; 60-69; 70-79; 80-104); race-ethnicity (non-Hispanic White; nonHispanic Black; Hispanic; non-Hispanic other); and level of education ( $0-8$ years; 9 or more years; missing). Though not identified as a characteristic commonly associated with death 
certificate error, we also include a dichotomous measure for biological sex (female; male).

\section{Death processing}

Two measures account for individual-level aspects of the context and processing of the death: location of death (home; hospital inpatient; hospital outpatient/emergency room (ER)/dead on arrival (DOA); nursing home; unknown other); and autopsy status (yes; no; unknown).

\section{Comorbidities}

Fourteen measures provide information on comorbidities reported on the death certificate. The first is the number of multiple causes of death reported on the death certificate $(0-15)$. The other 13 are binary measures (yes; no) that document whether specific ICD-10 codes were reported on the death certificate. Ten of the ICD-10 measures account for the top causes of death for adults with ID in the USA, ${ }^{35}$ inclusive of one external cause of death and internal causes of death (see table 2 for full listing and corresponding ICD-10 codes). One ICD-10 measure indicates whether an R-code indicating 'symptoms, signs and abnormal clinical and laboratory findings, not elsewhere classified' was reported on the death certificate. Because rates of inaccurate death certificate coding are high for people with cerebral palsy and Down syndrome, ${ }^{10}$ the remaining two ICD-10 measures indicate whether the decedent was comorbid for either cerebral palsy or Down syndrome.

State-level measures were defined by two concepts.

\section{Death certifier}

US states vary regarding whether they permit physician extenders ( 18 of the 50 US states permit physician extenders to certify), such as nurse practitioners and physician assistants, to certify death certificates, and whether they use medical examiners (appointed officials with medical training) and/or coroners (elected officials who may/may not have medical training) ${ }^{36}$ For this study, the original four-category measure of certifier from the US death certificate was combined with information from an original database indicating laws on whether states allow physician extenders (eg, nurse practitioners, physician's assistants) to certify, and whether states use medical examiners and/or coroners-an important distinction as coroners are typically elected officials who are not required to have medical training. This resulted in a six-category measure of certifier that accounted for state-level differences (medical examiner; coroner; medical examiner or coroner; physician; physician extenders; unknown).

\section{Fiscal support}

Each US state determines its own level of fiscal support for IDD services. State differences in policies and funding for IDD services can result in differential levels of access to care, including medical care, and influence knowledge of and attitudes towards disability. ${ }^{32} 3738$ Thus, indirectly, levels of state funding for IDD services may influence a certifier's previous level of interaction with and knowledge of people with ID, with comparatively higher levels of funding associated with more interaction with and knowledge of disability. State of the States in Intellectual and Developmental Disabilities collects information on states' fiscal efforts and standardises state spending on IDD services per $\$ 1000$ of state-wide personal income for comparison purposes. ${ }^{3739}$ We used the 2007-2016 State of the States in Intellectual and Developmental Disabilities data, adjusted to the 2017 dollar's value, to calculate average comparative state spending on IDD services in the 10 years prior to the death. The measure of fiscal support ranged from $\$ 1.11$ to $\$ 9.79$ in spending on IDD services per $\$ 1000$ of state-wide personal income.

\section{Analytical strategy}

Although rare, decedents who only had ID reported on their death certificate, with no other comorbidities reported on the death certificate, are an extreme example of diagnostic overshadowing. For this reason, we begin with a bivariate comparison of the distributions of individual-level and state-level characteristics of decedents who only had ID reported on their death certificate to decedents who had ID plus one or more comorbidity(ies) reported on their death certificate. As it is more common, the remainder of analysis focused on analysing associations between individual-level and state-level characteristics and inaccurate reporting of ID as the UCOD among decedents who had ID in addition to one or more comorbidity(ies) reported on their death certificate. Bivariate analysis was conducted with $\chi^{2}$ tests and Mann-Whitney tests, as continuous variables were not normally distributed, depending on the level of measurement of the independent variable. Fisher's exact test was used for $\chi^{2}$ analysis on the two occasions when the expected number of cases was less than 5 (ID severity, and race-ethnicity in table 1). To control for individual-level and state-level characteristics, multivariate analysis was conducted using two multilevel logistic regression models that controlled for all individual-level characteristics (model 1), then added the state-level characteristics (model 2).

The decision to maintain the missing categories for level of education, place of death, autopsy status and certifier, as opposed to using a complete case-control model, was made in order to account for the possibility that death certificates with incomplete data may be more likely to inaccurately report ID. If this is the case, then inaccurate reporting may simply be an artefact of instances when the process of completing the document was not as thorough, as opposed to instances when inaccurate reporting was due to uncertainties surrounding the death. Recognising the challenges of using separate categories for missing cases for the autopsy and certifier measures, we conducted sensitivity analysis using a complete case-control sample. Results were similar and are available on request.

\section{Patient and public involvement}

Neither patients nor the public were involved in any aspect of this study, inclusive of development of research question and design, outcome measures, analytical plan 
Table 1 Comparison of decedents with intellectual disability only (ID only) and intellectual disability plus one or more multiple causes of death (ID+1) reported on the death certificate, 2005-2017 US Multiple Cause-of-Death Mortality files, $n=26555$

\begin{tabular}{|c|c|c|c|c|c|}
\hline Variable & Categories & ID only \% (n) & ID+1 or more MCODs \% (n) & Test statistic & $P$ value \\
\hline \multirow[t]{3}{*}{ ID severity } & Mild/moderate & $0.84(1)$ & 2.55 (673) & 13.16 & 0.003 \\
\hline & Severe/profound & 30.25 (36) & $17.88(4727)$ & & \\
\hline & Unspecified & $68.91(82)$ & 79.57 (21 036) & & \\
\hline \multirow[t]{7}{*}{ Age } & $18-29$ & $4.20(5)$ & $5.92(1566)$ & 5.75 & 0.45 \\
\hline & 30-39 & $6.72(8)$ & $6.64(1755)$ & & \\
\hline & $40-49$ & $15.13(18)$ & 12.55 (3318) & & \\
\hline & $50-59$ & $29.41(35)$ & $22.97(6073)$ & & \\
\hline & $60-69$ & $17.65(21)$ & 23.76 (6281) & & \\
\hline & $70-79$ & $17.65(21)$ & $16.78(4436)$ & & \\
\hline & $80-104$ & $9.24(11)$ & $11.37(3007)$ & & \\
\hline \multirow[t]{2}{*}{ Sex } & Female & $45.38(54)$ & 45.54 (12 038) & 0.00 & 0.97 \\
\hline & Male & $54.62(65)$ & 54.46 (14 398) & & \\
\hline \multirow[t]{4}{*}{ Race-ethnicity } & Non-Hispanic White & 82.35 (98) & $80.03(21157)$ & 6.40 & 0.09 \\
\hline & Non-Hispanic Black & $15.97(19)$ & 12.66 (3348) & & \\
\hline & Hispanic & $1.68(2)$ & $5.48(1450)$ & & \\
\hline & Non-Hispanic other & $0.00(0)$ & $1.82(481)$ & & \\
\hline \multirow[t]{5}{*}{ Place of death } & Hospital inpatient & $5.88(7)$ & 36.20 (9570) & 50.42 & $<0.001$ \\
\hline & Outpatient/ER/DOA & $10.92(13)$ & $9.91(2619)$ & & \\
\hline & Home & $26.89(32)$ & $15.40(4071)$ & & \\
\hline & Nursing home & $43.70(52)$ & 30.65 (8102) & & \\
\hline & Other/unknown & $12.61(15)$ & $7.85(2074)$ & & \\
\hline \multirow[t]{3}{*}{ Education } & $0-8$ years & $68.91(82)$ & $59.07(15616)$ & 5.32 & 0.07 \\
\hline & $9+$ years & $16.81(20)$ & $24.98(6604)$ & & \\
\hline & Missing & $14.29(17)$ & 15.95 (4216) & & \\
\hline \multirow[t]{3}{*}{ Autopsy } & Yes & $5.04(6)$ & $5.67(1498)$ & 1.23 & 0.54 \\
\hline & No & $84.03(100)$ & 86.15 (22 775) & & \\
\hline & Unknown & $10.92(13)$ & $8.18(2163)$ & & \\
\hline \multicolumn{2}{|c|}{ Fiscal support, median } & 3.77 (119) & $4.16(26436)$ & 2.38 & 0.12 \\
\hline \multirow[t]{6}{*}{ Certifier } & Medical examiner & $8.40(10)$ & $3.67(971)$ & 28.34 & $<0.001$ \\
\hline & Physician & $54.62(65)$ & $53.12(14043)$ & & \\
\hline & Coroner & $1.68(2)$ & $1.31(347)$ & & \\
\hline & $\begin{array}{l}\text { Medical examiner/ } \\
\text { coroner }\end{array}$ & $10.08(12)$ & $3.42(903)$ & & \\
\hline & Physician extender & $10.08(12)$ & 17.66 (4668) & & \\
\hline & Unknown & $15.13(18)$ & $20.82(5504)$ & & \\
\hline \multicolumn{2}{|c|}{ Year of death, median } & 2010 (119) & $2010(26436)$ & 0.50 & 0.48 \\
\hline
\end{tabular}

Mann Whitney used for state funding and year of death; $\chi^{2}$ test used for all other variables. Fisher's exact test used for ID severity and race-ethnicity.

DOA, dead on arrival; ER, emergency room; ID, intellectual disability; MCODs, multiple causes of death.

and interpretation of results. All study participants were deceased and data are anonymous. Thus, results cannot and will not be disseminated to study participants.

\section{RESULTS}

Among the entire sample, $21.4 \%$ of decedents had ID inaccurately reported as their UCOD. For 119 out of the
26555 decedents $(<1 \%)$, ID was reported as the UCOD with no other comorbidities reported on the death certificate. Table 1 provides a comparison of the distribution of characteristics of those with only ID reported on their death certificate and those with ID plus at least one other comorbidity(ies) reported. The most remarkable differences were that decedents who had only ID reported on 
their death certificate were more likely than those who had ID plus other comorbidities reported to have their level of ID identified as severe/profound, to die in a nursing home and to have their death certificate certified by a medical examiner.

All subsequent analysis focused solely on decedents who had ID as well as one or more comorbidity(ies) reported on their death certificate, $21.1 \%$ of whom had ID inaccurately reported as their UCOD. Table 2 provides bivariate analysis of the association of each independent variable with whether ID was reported as the UCOD. ID was more commonly reported as the UCOD for decedents who: had severe/profound ID; died at younger ages; were male; were Hispanic; died at outpatient/ER locations or were DOA at a hospital; had 0-8 years of education; had an autopsy performed; lived in states with comparatively less spending on IDD services; or had their death certificate certified by a medical examiner or coroner. While ID was more commonly reported as the UCOD for decedents who had choking or pneumonitis on their death certificate, it was less common for all other comorbidities except for influenza/pneumonia, which was not statistically significant. Most strikingly, ID was reported as the UCOD for $55.3 \%$ of decedents with choking on their death certificate, but only for $3.1 \%$ of decedents with malignant neoplasms.

Bivariate associations for severity of disability, age, raceethnicity, education and the majority of the comorbidities were replicated in multivariate analysis. Multilevel multivariate results are reported in table 3 . In model 1 , the primary sociodemographic predictors of whether ID was reported as the UCOD were: severe/profound as opposed to mild/moderate or unspecified ID; older age; Hispanic ethnicity as opposed to non-Hispanic White race; and lower levels of education. In addition, ID was more likely to be reported as the UCOD for decedents who had, as opposed to those who did not have, influenza/pneumonia, pneumonitis, choking or an unspecified comorbidity (R-code); and less likely to be reported for decedents who had, as opposed to those who did not have, genitourinary diseases, diabetes, Alzheimer's/dementia, malignant neoplasms, chronic lower respiratory diseases, cerebrovascular diseases, cerebral palsy or Down syndrome. Two of these associations are worth noting: the $\mathrm{OR}$ for choking $(\mathrm{OR}=14.7$; $95 \%$ CI 12.9 to 16.6 ) was substantially higher than for any other measure, while the lowest OR was for malignant neoplasms $(\mathrm{OR}=0.1 ; 95 \% \mathrm{CI} 0.1$ to 0.2$)$. For autopsy status, those with an unknown status were more likely to have inaccurate reporting than those who did not have an autopsy. Associations remained consistent in model 2, which introduced the state-level measures. Neither state-level measure was associated with the reporting of ID as the UCOD. Consequently, the coefficient for statelevel differences in the reporting of ID as the UCOD only changed minimally from 0.21 to 0.20 .

\section{DISCUSSION}

Results from this study demonstrate that the inaccurate reporting of ID as the UCOD was associated with individual-level factors indicative of an increased amount of uncertainty surrounding the death. Some individuallevel factors signal the decedent may have experienced a comparatively lower frequency or quality of lifetime physician-patient interaction prior to death: more severe levels of disability, younger age, Hispanic ethnicity and lower levels of education. Others reveal that the decedent had comparatively fewer comorbidities reported on the death certificate, or had less specific comorbidities (unspecified causes of death) reported. Finally, ID was more likely to be inaccurately reported in instances when choking or a respiratory disease such as pneumonitis or influenza/ pneumonia was reported on the death certificate, but less likely in instances when a clearly specified internal cause of death was reported, such as malignant neoplasms or Alzheimer's/dementia. The individual-level measure of whether an autopsy was performed and both state-level measures did not predict the inaccurate reporting of ID as the UCOD.

The opposing results of increased risk of inaccurate reporting of ID associated with choking, but decreased risk of inaccurate reporting associated with malignant neoplasms offer a striking contrast of the effect of uncertainty on the reporting of ID. Although ambiguity can surround initial cancer diagnoses, a formal diagnosis is typically based on initial laboratory and imaging test results, and pathological standards and protocols that provide an increased amount of certainty. ${ }^{40}$ Consequently, among the comorbidities analysed in this study, malignant neoplasms were the strongest predictor of accurate reporting of ID-decedents with ID who had a cancer diagnosis on their death certificate were $83 \%$ less likely than those who did not to have their ID inaccurately reported as their UCOD. Conversely, chokingrelated deaths, especially for adults with developmental disability, ${ }^{41}$ are often surrounded by lingering questions about the casual sequence of the choking event, as well as the interplay of multiple factors that may have informed the event, such as actions of the decedent, quality of supervision and care and the possible effects of comorbidities and medications on the choking event. ${ }^{41-44}$ Illustrating the effect of this uncertainty on reporting, when choking was reported on the death certificate, ID was 14.7 times more likely to be inaccurately reported as the UCOD.

This leads to the question of what the certifier should do when the level of uncertainty surrounding the death of an individual with ID is high. In these instances, first and foremost, the certifier should recognise that ID is a disability, not an illness or disease, and therefore, not a valid UCOD. ${ }^{13}$ With this in mind, the certifier should then attempt to identify the actual disease or injury that caused the death, which may well be something like pneumonitis or choking. Demonstrating that accurately identifying the UCOD is possible, a prior study focused on adults who had their ID inaccurately reported on 
Table 2 Bivariate analysis of intellectual disability as underlying cause of death for decedents with intellectual disabiltiy plus one or more multiple causes of death reported on the death certificate, 2005-2017 US Multiple Cause-of-Death Mortality files, $n=26436$

\begin{tabular}{|c|c|c|c|c|c|}
\hline & & No\% (n) & Yes\% (n) & Test statistic & $P$ value \\
\hline \multicolumn{6}{|l|}{ ID severity } \\
\hline Mild/moderate (ICD-10 F70-72) & & $90.04(606)$ & $9.96(67)$ & 318.89 & $<0.001$ \\
\hline Severe/profound (ICD-10 F73-74) & & $69.90(3304)$ & $30.10(1423)$ & & \\
\hline Unspecified (ICD-10 F78-79) & & 80.63 (16 962) & 19.37 (4074) & & \\
\hline \multicolumn{6}{|l|}{ Age } \\
\hline $18-29$ & & $77.97(1221)$ & $22.03(345)$ & 111.31 & $<0.001$ \\
\hline 30-39 & & $77.26(1356)$ & $22.74(399)$ & & \\
\hline $40-49$ & & $75.38(2501)$ & $24.62(817)$ & & \\
\hline $50-59$ & & $76.37(4638)$ & $23.63(1435)$ & & \\
\hline $60-69$ & & $80.07(5029)$ & $19.93(1252)$ & & \\
\hline $70-79$ & & $81.76(3627)$ & $18.24(809)$ & & \\
\hline $80-104$ & & $93.14(2500)$ & $16.86(507)$ & & \\
\hline Female & & $79.71(11276)$ & 20.29 (3122) & 7.71 & 0.01 \\
\hline Male & & 78.32 (9596) & $21.68(2442)$ & & \\
\hline \multicolumn{6}{|l|}{ Race-ethnicity } \\
\hline Non-Hispanic White & & 78.85 (16 683) & 21.15 (4474) & 10.96 & 0.01 \\
\hline Non-Hispanic Black & & 79.69 (2668) & $20.31(680)$ & & \\
\hline Hispanic & & $77.10(1118)$ & $22.90(332)$ & & \\
\hline Non-Hispanic other & & $83.78(78)$ & $16.22(403)$ & & \\
\hline \multicolumn{6}{|l|}{ Place of death } \\
\hline Hospital inpatient & & $78.53(7515)$ & $21.47(2055)$ & 52.44 & $<0.001$ \\
\hline Outpatient/ER/DOA & & $74.19(1943)$ & $25.81(676)$ & & \\
\hline Home & & $80.15(3263)$ & $19.85(808)$ & & \\
\hline Nursing home & & $80.51(6523)$ & 19.49 (1579) & & \\
\hline Other/unknown & & $78.50(1628)$ & $21.50(446)$ & & \\
\hline \multicolumn{6}{|l|}{ Education } \\
\hline $0-8$ years & & $77.56(12111)$ & 22.44 (3505) & 54.36 & $<0.001$ \\
\hline $9+$ years & & $81.94(5411)$ & $18.06(1193)$ & & \\
\hline Missing & & $79.46(3350)$ & $20.54(866)$ & & \\
\hline $\begin{array}{l}\text { Number of comorbidities (1-15), } \\
\text { median }(n)\end{array}$ & & $4(20872)$ & $4(5683)$ & 460.71 & $<0.001$ \\
\hline \multicolumn{6}{|l|}{ Autopsy } \\
\hline Yes & & $73.16(1096)$ & $26.84(402)$ & 38.83 & $<0.001$ \\
\hline No & & $79.51(18$ 108) & $20.49(4667)$ & & \\
\hline Unknown & & $77.12(1668)$ & $22.88(495)$ & & \\
\hline \multirow{2}{*}{$\begin{array}{l}\text { Heart disease (ICD-10 I00-I09; I11; } \\
\text { I13; I20-I51) }\end{array}$} & Yes & 84.19 (7899) & $15.81(1483)$ & 240.33 & $<0.001$ \\
\hline & No & 76.07 (12 973) & $23.93(4081)$ & & \\
\hline \multirow[t]{2}{*}{ Influenza/pneumonia (ICD-10 J09-J18) } & Yes & 79.24 (3828) & $20.76(1003)$ & 0.29 & 0.59 \\
\hline & No & 78.89 (17 044) & $21.11(4561)$ & & \\
\hline \multirow[t]{2}{*}{ Pneumonitis (ICD-10 J69) } & Yes & 73.95 (3174) & 26.05 (1118) & 77.13 & $<0.001$ \\
\hline & No & 79.92 (17 698) & 20.08 (4446) & & \\
\hline $\begin{array}{l}\text { Genitourinary diseases (ICD-10 N00- } \\
\text { N07; N17-N19; N25-27; N39) }\end{array}$ & Yes & 86.90 (2482) & $13.10(5190)$ & 121.84 & $<0.001$ \\
\hline
\end{tabular}


Table 2 Continued

\begin{tabular}{|c|c|c|c|c|c|}
\hline & & No\% (n) & Yes \% (n) & Test statistic & $P$ value \\
\hline & No & 77.99 (18 390) & $22.00(5190)$ & & \\
\hline \multirow[t]{2}{*}{ Diabetes (ICD-10 E10-E14) } & Yes & $90.77(2154)$ & $9.23(219)$ & 219.12 & $<0.001$ \\
\hline & No & 77.79 (18 718) & $22.21(5345)$ & & \\
\hline \multirow[t]{2}{*}{ Choking (ICD-10 W78-W80) } & Yes & $44.73(1061)$ & $55.27(1311)$ & 1800.00 & $<0.001$ \\
\hline & No & $82.33(19811)$ & $17.67(4253)$ & & \\
\hline \multirow{2}{*}{$\begin{array}{l}\text { Alzheimer's/dementia (ICD-10 G30, } \\
\text { F03) }\end{array}$} & Yes & $91.86(2076)$ & $8.14(184)$ & 247.69 & $<0.001$ \\
\hline & No & $77.75(18796)$ & $22.25(5380)$ & & \\
\hline \multirow{2}{*}{$\begin{array}{l}\text { Malignant neoplasms (ICD-10 C00- } \\
\text { C97) }\end{array}$} & Yes & $96.92(2016)$ & $3.08(64)$ & 438.73 & $<0.001$ \\
\hline & No & $77.42(18$ 856) & $22.58(5500)$ & & \\
\hline \multirow{2}{*}{$\begin{array}{l}\text { Chronic lower respiratory diseases } \\
\text { (ICD-10 J40-J47) }\end{array}$} & Yes & $91.26(1535)$ & $8.74(147)$ & 163.74 & $<0.001$ \\
\hline & No & 78.12 (19 337) & $21.88(5417)$ & & \\
\hline \multirow{2}{*}{$\begin{array}{l}\text { Cerebrovascular diseases (ICD-10 } \\
\text { I60-169) }\end{array}$} & Yes & $94.25(1328)$ & $5.75(81)$ & 209.62 & $<0.001$ \\
\hline & No & 78.09 (19 544) & $21.91(5483)$ & & \\
\hline \multirow[t]{2}{*}{ Unspecified (ICD-10 R00-R99) } & Yes & $82.77(8306)$ & $17.23(2948)$ & 312.54 & $<0.001$ \\
\hline & No & $73.80(12566)$ & $26.20(2616)$ & & \\
\hline \multirow[t]{2}{*}{ Cerebral palsy (ICD-10 G80) } & Yes & $93.57(2577)$ & $6.43(177)$ & 395.44 & $<0.001$ \\
\hline & No & 77.25 (18 295) & $22.75(5387)$ & & \\
\hline \multirow[t]{2}{*}{ Down syndrome (ICD-10 Q90) } & Yes & $91.58(1001)$ & $8.42(92)$ & 109.44 & $<0.001$ \\
\hline & No & $78.41(19871)$ & 21.59 (5472) & & \\
\hline Fiscal support, median & & 4.19 (20 872) & $4.04(5683)$ & 6.93 & 0.01 \\
\hline \multicolumn{6}{|l|}{ Certifier } \\
\hline Medical examiner & & $74.36(722)$ & $25.64(249)$ & 44.58 & $<0.001$ \\
\hline Physician & & 79.95 (11 228) & $20.05(2815)$ & & \\
\hline Coroner & & $74.06(257)$ & $25.94(90)$ & & \\
\hline Medical examiner/coroner & & $73.20(661)$ & $26.80(242)$ & & \\
\hline Physician extender & & $78.43(3661)$ & $21.57(1007)$ & & \\
\hline Unknown & & $78.91(4343)$ & $21.09(1161)$ & & \\
\hline Year of death, median & & 2010.40 (20 872) & $2010.67(5683)$ & 25.12 & $<0.001$ \\
\hline
\end{tabular}

Mann Whitney used for number of comorbidities, state funding and year of death; $\chi^{2}$ test used for all other variables.

DOA, dead on arrival; ER, emergency room; ICD-10, International Statistical Classification of Diseases and Related Health Problems, Tenth Revision; ID, intellectual disability.

their death certificate successfully identified a legitimate UCOD in $98.8 \%$ of cases. ${ }^{10}$ In the extremely rare instances in which, after careful consideration of all information, a valid UCOD cannot be identified and investigation by a medical examiner or coroner is unwarranted, the CDC states that the UCOD can be reported as 'unspecified natural causes'. ${ }^{45}$ While not ideal, doing so is preferable to inaccurately ascribing death to disability. Finally, and critical to ensuring the ability to monitor mortality trends for people with ID, the certifier should report the ID in Part II of the death certificate as a condition that was present at the time of death. ${ }^{13}$
Limitations to this study relate to the data used for analysis. It is likely that some decedents with ID in the USA did not have their disability reported on their death certificate. As there are no reliable estimates of the percentage of the US adult population with ID that do not have a comorbid developmental disability, such as Down syndrome, it is not possible to determine the representativeness of this sample. Thus, it is important to recognise that results only apply to adults with ID who had their disability reported on their death certificate. In addition, there were limitations in the data regarding the specificity of information reported on the death certificate. 
Table 3 Multilevel multivariate analysis of intellectual disability as underlying cause of death for decedents with intellectual disabiltiy plus one or more multiple causes of death reported on the death certificate, 2005-2017 US Multiple Cause-of-Death Mortality files, $n=26436$

\begin{tabular}{|c|c|c|c|c|}
\hline & \multicolumn{2}{|c|}{$\begin{array}{l}\text { Model 1: individual-level } \\
\text { characteristics }\end{array}$} & \multicolumn{2}{|c|}{$\begin{array}{l}\text { Model 2: individual-level and state-level } \\
\text { characteristics }\end{array}$} \\
\hline & OR & $95 \% \mathrm{Cl}$ & OR & $95 \% \mathrm{Cl}$ \\
\hline \multicolumn{5}{|l|}{ ID severity (Ref: Severe/profound) } \\
\hline Mild/moderate & $0.40^{\star * *}$ & 0.30 to 0.53 & $0.40^{\star \star *}$ & 0.30 to 0.53 \\
\hline Unspecified & $0.61^{\star \star *}$ & 0.56 to 0.67 & $0.61^{\star \star \star}$ & 0.56 to 0.66 \\
\hline \multicolumn{5}{|l|}{ Age (Ref: 18-29) } \\
\hline $30-39$ & 0.87 & 0.72 to 1.05 & 0.87 & 0.72 to 1.05 \\
\hline $40-49$ & 0.95 & 0.80 to 1.13 & 0.95 & 0.80 to 1.12 \\
\hline $50-59$ & 0.95 & 0.81 to 1.11 & 0.95 & 0.80 to 1.11 \\
\hline $60-69$ & $0.81^{*}$ & 0.69 to 0.95 & $0.81^{*}$ & 0.69 to 0.95 \\
\hline $70-79$ & $0.81^{*}$ & 0.68 to 0.96 & $0.81^{*}$ & 0.68 to 0.96 \\
\hline $80-104$ & $0.83^{*}$ & 0.68 to 1.00 & 0.83 & 0.68 to 1.00 \\
\hline Female & 1.03 & 0.96 to 1.10 & 1.03 & 0.96 to 1.10 \\
\hline \multicolumn{5}{|l|}{$\begin{array}{l}\text { Race-ethnicity } \\
\text { (Ref: Non-Hispanic White) }\end{array}$} \\
\hline Non-Hispanic Black & 0.96 & 0.86 to 1.07 & 0.96 & 0.86 to 1.07 \\
\hline Hispanic & $1.20^{*}$ & 1.03 to 1.40 & $1.20^{*}$ & 1.03 to 1.40 \\
\hline Non-Hispanic other & 0.76 & 0.58 to 1.01 & 0.76 & 0.57 to 1.00 \\
\hline \multicolumn{5}{|l|}{$\begin{array}{l}\text { Place of death } \\
\text { (Ref: Hospital inpatient) }\end{array}$} \\
\hline Hospital outpatient/ER/DOA & 1.02 & 0.91 to 1.16 & 1.02 & 0.90 to 1.16 \\
\hline Home & 0.90 & 0.81 to 1.01 & 0.90 & 0.81 to 1.01 \\
\hline Nursing home & 1.07 & 0.97 to 1.17 & 1.07 & 0.97 to 1.17 \\
\hline Other/unknown & 1.00 & 0.87 to 1.14 & 0.99 & 0.87 to 1.14 \\
\hline \multicolumn{5}{|l|}{ Education (Ref: 0-8 years) } \\
\hline $9+$ years & $0.86^{\star \star}$ & 0.79 to 0.94 & $0.86^{\star \star}$ & 0.78 to 0.94 \\
\hline Missing & 0.92 & 0.83 to 1.01 & 0.92 & 0.83 to 1.01 \\
\hline Number of comorbidities (1-15) & $0.63^{\star \star *}$ & 0.61 to 0.65 & $0.63^{\star \star \star}$ & 0.61 to 0.65 \\
\hline \multicolumn{5}{|l|}{ Autopsy (Ref: No) } \\
\hline Yes & 0.92 & 0.80 to 1.07 & 0.91 & 0.78 to 1.07 \\
\hline Unknown & $1.24^{\star *}$ & 1.08 to 1.43 & $1.24^{\star \star}$ & 1.07 to 1.42 \\
\hline Heart disease & 0.95 & 0.88 to 1.03 & 0.95 & 0.88 to 1.03 \\
\hline Influenza/pneumonia & $1.25^{\star \star *}$ & 1.13 to 1.37 & $1.25^{\star \star \star}$ & 1.13 to 1.37 \\
\hline Pneumonitis & $1.27^{\star \star \star}$ & 1.15 to 1.40 & $1.27^{\star \star \star}$ & 1.16 to 1.40 \\
\hline Genitourinary diseases & $0.81^{\star \star}$ & 0.72 to 0.92 & 1.03 & 0.91 to 1.17 \\
\hline Diabetes & $0.75^{\star \star \star}$ & 0.64 to 0.88 & $0.75^{\star \star \star}$ & 0.64 to 0.88 \\
\hline Choking & $14.65^{\star \star \star}$ & 12.94 to 16.56 & $14.64^{\star \star \star}$ & 12.94 to 16.58 \\
\hline Alzheimer's/dementia & $0.33^{\star \star \star}$ & 0.28 to 0.40 & $0.33^{\star \star \star}$ & 0.28 to 0.40 \\
\hline Malignant neoplasms & $0.13^{\star \star \star}$ & 0.10 to 0.17 & $0.13^{\star \star \star}$ & 0.10 to 0.17 \\
\hline Chronic lower respiratory diseases & $0.54^{\star \star \star}$ & 0.45 to 0.65 & $0.54^{\star \star \star}$ & 0.45 to 0.65 \\
\hline Cerebrovascular diseases & $0.28^{\star \star \star}$ & 0.22 to 0.35 & $0.28^{\star * *}$ & 0.22 to 0.35 \\
\hline Unspecified (R-code) & $2.81^{\star \star \star}$ & 2.60 to 3.03 & $2.81^{\star \star \star}$ & 2.60 to 3.03 \\
\hline Cerebral palsy & $0.18^{\star \star *}$ & 0.15 to 0.21 & $0.18^{\star * *}$ & 0.15 to 0.21 \\
\hline Down syndrome & $0.32^{\star \star \star}$ & 0.25 to 0.40 & $0.32^{\star \star \star}$ & 0.25 to 0.40 \\
\hline
\end{tabular}


Model 1: individual-level characteristics $95 \% \mathrm{Cl}$

Model 2: individual-level and state-leve characteristics

OR $\quad 95 \% \mathrm{Cl}$

\begin{tabular}{|c|c|c|c|c|}
\hline Fiscal support & & & 0.97 & 0.93 to 1.01 \\
\hline \multicolumn{5}{|l|}{ Certifier (Ref: Medical examiner) } \\
\hline Physician & & & 1.02 & 0.85 to 1.23 \\
\hline Coroner & & & 0.97 & 0.67 to 1.39 \\
\hline Medical examiner or coroner & & & 1.09 & 0.84 to 1.41 \\
\hline Physician extender & & & 1.04 & 0.83 to 1.29 \\
\hline Unknown & & & 1.07 & 0.88 to 1.32 \\
\hline Year of death & $1.04^{\star \star \star}$ & 1.03 to 1.05 & $1.04^{\star \star \star}$ & 1.03 to 1.05 \\
\hline Intercept & 2.06 & 1.66 to 2.55 & $2.27^{\star \star \star}$ & 1.64 to 3.14 \\
\hline State intercept & 0.21 & 0.16 to 0.29 & 0.20 & 0.15 to 0.28 \\
\hline Likelihood ratio test & 80.35 & & 52.47 & \\
\hline Akaike information criterion (AIC) & 21266.38 & & 21275.23 & \\
\hline
\end{tabular}

${ }^{* * *} p<.0 .001 ;{ }^{* *} p<.01 ;{ }^{*} p<.05$

DOA, dead on arrival; ER, emergency room; ID, intellectual disability.

The severity level of ID is reported as 'unspecified' on $79.5 \%$ of the death certificates during the study period. Although decedents with unspecified ID were less likely than those with severe/profound ID to have inaccurate reporting of their disability, we cannot determine what this association is capturing due to the inexactness of the ID category. Autopsy status was only predictive of inaccurate reporting for the 'unknown' category, and certifier was not predictive at all. However, autopsy status was reported as 'unknown' for $8.2 \%$ of decedents, and certifier category was reported 'unknown' for $20.8 \%$ of decedents. Therefore, we cannot know the effect of having the autopsy status or certifier type clearly specified for these cases. This limitation applies to education as well, as $16.0 \%$ of cases were missing the level of education of the decedent.

Efforts to reduce premature mortality among adults with ID are highly dependent on death certificate data. Thus, medical providers should strive to accurately report the cause of death for this population. Evidence from this study demonstrates that a higher level of uncertainty surrounding a death is associated with increased likelihood of ID being inaccurately reported as the UCOD. Some level of uncertainty is typically present in all medicine,${ }^{46-48}$ especially death certification. ${ }^{19}$ It is important in these moments that medical providers rely on empirical information, as opposed to assumptions or stereotypes about certain groups of people, especially marginalised groups such as adults with ID. ${ }^{46}{ }^{49}$ It is clear that ID is not a disease or injury, but a disability. As such, even when increased uncertainty surrounds the death of an individual with ID, the medical provider should not revert to diagnostic overshadowing and report the disability as the UCOD. As is the case with other marginalised populations, engaging in this type of stereotyping in the midst of clinical uncertainty does no more than compound the disparities experienced by this population. ${ }^{46}$

Contributors SL acquired and had full access to all of the data in the study and takes responsibility for the integrity of the data and the accuracy of the data analysis. SL and MT conceptualised and designed the study. SL analysed the data. SL and MT interpreted the results. SL and EB drafted the manuscript. SL, MT and EB critically revised the manuscript for intellectual content.

Funding Research reported in this publication was supported by the National Institute on Aging (NIA; grant R03AG065638). This research also benefited from NIA Center (grant P30AG066583), Center for Aging and Policy Studies. State of the States in Intellectual and Developmental Disabilities received support from the Administration on Community Living, US Department of Health and Human Services (grant number HHS 90DNPA0003-01-00).

Disclaimer The content is solely the responsibility of the authors and does not necessarily represent the official views of the National Institutes of Health. Grantees undertaking projects under government sponsorship are encouraged to express freely their findings and conclusions. Points of view or opinions do not therefore necessarily represent official ACL policy.

Competing interests None declared.

Patient and public involvement Patients and/or the public were not involved in the design, or conduct, or reporting, or dissemination plans of this research.

Patient consent for publication Not required.

Ethics approval Ethical approval was not required for this study as US Multiple Cause-of-Death Mortality files, provided by the National Center for Health Statistics (NCHS), Centers for Disease Control and Prevention, are fully deidentified by NCHS.

Provenance and peer review Not commissioned; externally peer reviewed.

Data availability statement All data are available upon approved request from the National Vital Statistics System, Centers for Disease Control and Prevention.

Open access This is an open access article distributed in accordance with the Creative Commons Attribution Non Commercial (CC BY-NC 4.0) license, which permits others to distribute, remix, adapt, build upon this work noncommercially, and license their derivative works on different terms, provided the original work is properly cited, appropriate credit is given, any changes made indicated, and the use is non-commercial. See: http://creativecommons.org/ licenses/by-nc/4.0/. 
ORCID iD

Scott D Landes http://orcid.org/0000-0002-2151-7805

\section{REFERENCES}

1 Spong CY, Bianchi DW. Improving public health requires inclusion of underrepresented populations in research. JAMA 2018;319:337-8.

2 Krahn GL, Fox MH. Health disparities of adults with intellectual disabilities: what do we know? what do we do? J Appl Res Intellect Disabil 2014;27:431-46.

3 Krahn GL, Walker DK, Correa-De-Araujo R. Persons with disabilities as an unrecognized health disparity population. Am J Public Health 2015;105 Suppl 2:S198-206.

4 Peña-Guzmán DM, Reynolds JM. The harm of ableism: medical error and epistemic injustice. Kennedy Inst Ethics J 2019;29:205-42.

5 Jopp DA, Keys CB. Diagnostic overshadowing reviewed and reconsidered. Am J Ment Retard 2001;106:416-33.

6 Ali A, Scior K, Ratti V, et al. Discrimination and other barriers to accessing health care: perspectives of patients with mild and moderate intellectual disability and their carers. PLoS One 2013;8:e70855.

7 Ouellette-Kuntz H. Understanding health disparities and inequities faced by individuals with intellectual disabilities. Journal of Applied Research in Intellectual Disabilities 2005;18:113-21.

8 Hollins S, Attard MT, von Fraunhofer N. Mortality in people with learning disability: risks, causes, and death certification findings in London. Dev Med Child Neurol 1998;40:50-6.

9 Centers for Disease Control and Prevention (CDC). U.S. standard certificate of death. CDC, 2003. Available: https://www.cdc.gov/ nchs/data/dvs/death11-03final-acc.pdf [Accessed December 17, 2020].

10 Landes SD, Stevens JD, Turk MA. Obscuring effect of coding developmental disability as the underlying cause of death on mortality trends for adults with developmental disability: a crosssectional study using us mortality data from 2012 to 2016 . BMJ Open 2019;9:e026614:1-10.

11 National Center for Health Statistics. Physicians' Handbook on medical certification of death. centers for disease control and prevention, 2003. Available: https://www.cdc.gov/nchs/data/misc/ hb_cod.pdf [Accessed November 29, 2018].

12 Schalock RL, Borthwick-Duffy SA, Bradley VJ. Intellectual disability: Definition, classification, and systems of supports. 11th ed. Washington, DC: AAIDD, 2010.

13 Landes SD, Turk MA, Lauer E. Recommendations for accurately reporting intellectual and developmental disabilities on death certificates. Am J Prev Med 2020;59:892-5.

14 Landes SD, Stevens JD, Turk MA. Heterogeneity in age at death for adults with developmental disability. J Intellect Disabil Res 2019;63:1482-7.

15 Jha P. Counting the dead is one of the world's best investments to reduce premature mortality. Hypothesis 2012;10:e3.

16 Landes SD, Peek CW. Death by mental retardation? The influence of ambiguity on death certificate coding error for adults with intellectual disability. J Intellect Disabil Res 2013;57:1183-90.

17 Lenfant C, Friedman L, Thom T. Fifty years of death certificates: the Framingham heart study. Ann Intern Med 1998;129:1066-7.

18 Wall MM, Huang J, Oswald J, et al. Factors associated with reporting multiple causes of death. BMC Med Res Methodol 2005;5:4.

19 Timmermans S. Postmortem: How medical examiners explain suspicious deaths. Chicago: University of Chicago Press, 2006

20 Hanzlick R, Combs D. Medical examiner and coroner systems: history and trends. JAMA 1998;279:870-4.

21 Kircher T, Nelson J, Burdo $\mathrm{H}$. The autopsy as a measure of accuracy of the death certificate. N Engl J Med 1985;313:1263-9.

22 Pritt BS, Hardin NJ, Richmond JA, et al. Death certification errors at an academic institution. Arch Pathol Lab Med 2005;129:1476-9.

23 Ong LM, de Haes JC, Hoos AM, et al. Doctor-patient communication: a review of the literature. Soc Sci Med 1995;40:903-18.

24 De Alba I, Sweningson JM. English proficiency and physicians' recommendation of Pap smears among Hispanics. Cancer Detect Prev 2006;30:292-6.

25 Mayo RM, Sherrill WW, Sundareswaran P, et al. Attitudes and perceptions of Hispanic patients and health care providers in the treatment of Hispanic patients: a review of the literature. Hispanic Health Care International 2007;5:64-72.

26 Seijo R, Gomez H, Freidenberg J. Language as a communication barrier in medical care for Hispanic patients. Hisp J Behav Sci 1991;13:363-76.

27 Willems S, De Maesschalck S, Deveugele M, et al. Socio-economic status of the patient and doctor-patient communication: does it make a difference? Patient Educ Couns 2005;56:139-46.

28 Verlinde E, De Laender N, De Maesschalck S, et al. The socia gradient in doctor-patient communication. Int $J$ Equity Health 2012;11:12.

29 Chew KL, lacono T, Tracy J. Overcoming communication barriers working with patients with intellectual disabilities. Aust Fam Physician 2009;38:10.

30 Stringer K, Ryan BL, Terry AL. Primary care of adults with severe and profound intellectual and developmental disabilities: family physicians' perspectives on patient-physician relationships. Can Fam Physician 2019;65:S59-65.

31 Wullink M, Veldhuijzen W, Lantman-de Valk HMvanS, et al. Doctorpatient communication with people with intellectual disability--a qualitative study. BMC Fam Pract 2009;10:82.

32 Imrie R. Disabling environments and the geography of access policies and practices. Disabil Soc 2000;15:5-24.

33 Baird PA, Sadovnick AD. Underlying causes of death in Down syndrome: accuracy of British Columbia death certificate data. Can J Public Health 1990;81:456-61.

34 State of the states in Intelletual and developmental disabilities, 2020. Available: https://stateofthestates.org/

35 Landes SD, Stevens JD, Turk MA. Cause of death in adults with intellectual disability in the United States. J Intellect Disabil Res 2021;65:47-59.

36 Stevens JD, Landes SD. Assessing state level variation in signature authority and cause of death accuracy, 2005-2017. Public Health Reports, 2021: 1-21.

37 Braddock D, Hemp R, Rizzolo MC. The State of the States in developmental disabilities: Emerging from the Great Recession. Washington, DC: American Association on Intellectual and Developmental Disabilities, 2015.

38 Friedman $\mathrm{C}$. The relationship between disability prejudice and institutionalization of people with intellectual and developmental disabilities. Intellect Dev Disabil 2019;57:263-73.

39 Tanis ES. The cost of doing business: institutional bias and community-based services and supports. Geo J on Poverty L \& Pol'y 2019;27:291.

40 College of American Pathologists. Cancer protocol templates. College of American pathologists, 2020. Available: https://www. cap.org/protocols-and-guidelines/cancer-reporting-tools/cancerprotocol-templates [Accessed August 13, 2020].

41 Hanley MJ. Exploring the social context of choking and its implications for care. University of Tasmania, 2018.

42 Kramarow E, Warner M, Chen L-H. Food-related choking deaths among the elderly. Inj Prev 2014;20:200-3.

43 Wick R, Gilbert JD, Byard RW. Café coronary syndrome-fatal choking on food: an autopsy approach. J Clin Forensic Med 2006;13:135-8.

44 Dahm MR, Georgiou A, Balandin S, et al. Health information and the quality and safety of care for people with disability: an analysis of Australian reports of reviewable deaths in residential care. J Patient Saf 2018. doi:10.1097/PTS.0000000000000550. [Epub ahead of print: 13 Nov 2018].

45 CDC. Possible solutions to common problems in death certification. centers for disease control and prevent, National center for health statistics, 2015. Available: https://www.cdc.gov/nchs/nvss/writingcod-statements/death_certification_problems.htm [Accessed August 17, 2020.].

46 Balsa AI, McGuire TG. Prejudice, clinical uncertainty and stereotyping as sources of health disparities. J Health Econ 2003;22:89-116.

47 Good M-JD. American medicine: the quest for competence. Univ of California Press, 1998.

48 Timmermans S, Angell A, Medicine E-B. Clinical uncertainty, and learning to doctor. Journal of Health and Social Behavior 2001;42:342-59.

49 Balsa Al, McGuire TG. Statistical discrimination in health care. J Health Econ 2001;20:881-907. 